\title{
Speaking and writing: Comparisons of two psycholinguistic siblings
}

\author{
DONNA A. VAN DE WATER, LAURA A. MONTI, PAUL B. KIRCHNER, \\ and DANIEL C. O'CONNELL \\ Loyola University of Chicago, Chicago, Illinois
}

\begin{abstract}
An identical composition and recall task was used to compare writing and speaking in terms of their temporal organization. A common cutoff point of $0.1 \mathrm{sec}$ was used for minimum duration of pauses. Speakers took only a fourth of the time taken by writers, but spoke more than half again as many syllables as writers wrote. Mean durations of pauses for writing and speaking were equivalent (110 and $0.97 \mathrm{sec}$, respectively), but the respective distributions of pauses differed dramatically: In writing, a far greater number of pauses per syllable led to shorter phrases (segmentation between and even within individual words), whereas speaking was characterized by fewer pauses per syllable and consequently longer phrases (segmentation between syntactic units). Pauses at syntactic positions (i.e., after punctuation) were the least frequent pauses in writing, although they were the longest in mean duration.
\end{abstract}

We need only consult a modern psycholinguistics textbook or journal to become aware of the shocking neglect of writing. Clark and Clark (1977) maintained that psycholinguistics is "the study of listening, speaking, and the acquisition of these skills by children" ( $p$. vii; also Dell, 1986). Writing is speaking's neglected sibling; when allowed in the house at all, it is most often required to remain on the page and play the role of the written.

Writing is, in fact, a skilled motor behavior that takes place in time and reveals human psychology to a remarkable degree, very much as does speaking. But writing has hardly been recognized at all in the research history of the psycholinguistic family (see Kowal and O'Connell, 1986).

Among the reasons for this neglect are the disrepute into which graphological studies have fallen, the difficulties of instrumentation for observing writing in real time, and (to return to our metaphor) the attractiveness of the other sibling, which has been considerably enhanced by the recent interest of linguists. Small wonder, then, that discussions of writing are frequently limited to composition and relegated to educational research, or are summarized in comparisons to speaking that do not "surpass the truism that speech rate is indeed faster than writing rate" (Kowal \& O'Connell, 1986, p. 129).

Nevertheless, the relatively early study by van Bruggen (1946) remains important. Using a kymograph to measure the time course of writing to $0.1 \mathrm{sec}$, van Bruggen expressed in words per minute differences between rates of writing from memory and rates of composing. Because syllables per word can vary appreciably from one genre of writing to another, the words per minute index appears to have reflected artifactual results.

Horowitz and Berkowitz (1964), using a within-subjects design, found that speech rate is more than seven times

Address correspondence to Daniel C. O'Connell, Psychology Department, Damen Hall 619, Loyola University of Chicago, 6525 North Sheridan Road, Chicago, IL 60626. as fast as writing rate (speech, 2.39 syllables/sec; writing, 0.33 syllables $/ \mathrm{sec}$ ). Tannenbaum, Williams, and Wood (1967) compared speaking and typing and found the latter to be characterized by longer but fewer pauses than speaking. Tannenbaum et al. explained that "the writing situation affords the encoder the luxury to "stop and think'-without fear of losing his audience, and without the hazard of losing track of his sequence of expression"' (p. 214). Unfortunately, their finding is an artifact produced by the use of a 0.3 -sec cutoff point for speech pauses and $3.0 \mathrm{sec}$ for the typing task.

Blass and Siegman (1975) recorded pause time in speaking and writing by stopwatch, with a cutoff point (for minimum measured duration of pauses) of $2.0 \mathrm{sec}$. Like Tannenbaum et al. (1967), they hypothesized a lower percentage of offtime/total time and a higher production rate (in words/sec) for speaking than for writing: "The less pressure the subject experiences, the greater his freedom to take his time, to think before and during his responses and to plan and construct his responses more carefully" (p. 23). However, this rationale is basically associated with different social settings for speaking and for writing. Accordingly, Blass and Siegman (1975) found speech and writing rates of 3.03 and 0.43 words/sec, respectively (a factor of 7.0, compared to that of 7.2 in Horowitz \& Berkowitz, 1964); however, writing yielded a lower percentage of offtime/total time than did speaking.

Gould and Quinones (1978) described a videotape methodology for recording the temporal course of writing. Gould $(1978,1980)$ and Gould and Boies (1978) compared speaking and writing of letters. Despite shifts in methods of measurement and in the presentation of findings, Gould (1980) insisted that "planning time was a constant proportion of total composition time"' (p. 112). The proportion was two thirds.

Matsuhashi (1981, Matsuhashi \& Cooper, 1978, Spittle \& Matsuhashi, 1981) compared reporting, persuad- 
ing, and generalizing compositions in terms of their temporal organization. They too used videotaped recordings of writing and adopted a 0.1 -sec cutoff point for minimum duration of pauses. Extreme variability of pause duration was found, but writing rates for the three tasks were similar $(0.25,0.22$, and 0.18 words/sec, respectively). A control condition (copying) yielded a writing rate of 0.27 words/sec and a shorter pause duration $(0.87 \mathrm{sec})$. There seems to have been some confusion in these studies as to which pause positions should be expected to yield longer and which to yield shorter pauses (Kowal \& O'Connell, 1986). The studies were not carefully controlled, and very few subjects were used.

To summarize this brief review of the literature, we must concur with Kowal and O'Connell (1986) and conclude that previous methodological approaches and data analyses have "made it clear that for the most part the research questions have not been settled" (p. 122). It is not particularly enlightening to compare "the extremes of spoken and written language"' (Chafe, 1985, p. 122), that is, informal speaking and formal prose, and come up with anecdotal generalizations, as Chafe has recently done. The specific question address here was, what is the relationship of writing and speaking in terms of their temporal organization?

\section{METHOD}

A comparison of the temporal course of writing and speaking requires that we keep everything constant, as far as possible, across the two modalities, except the modalities themselves. To date this has not been done properly. Hence, the present study adopted a common cutoff point of $0.1 \mathrm{sec}$ for minimum duration of pauses. Instructions, experimental setting, experimenter, and task were the same for both speaking and writing modalities. Kowal and O'Connell (1986) suggested the use of both within-subjects designs and multiple tasks in order to control variability and diversify the comparisons themselves. To this end, we used a within-subjects design consisting of a composition (C) and recall (R) task. The $\mathbf{4 0}$ subjects were run individually. All were undergraduate students at Loyola University of Chicago and were native speakers of English. For each modality, writing (W) and speaking (S), two groups of 10 subjects each (5 men and 5 women, as a control, not as an analytic condition) were asked to examine a Thematic Aperception Test (TAT) picture (a man and woman seated on a park bench by a river) and to write or speak a story about the picture. The two groups were designated picture (P) and no picture (NP). The former received the picture for the recall condition and the latter did not, and both groups were tested exactly 1 week later. They were asked to repeat their story of the previous week as exactly as possible (in the same modalitiy as the original version).

The design was accordingly a $2 \times 2 \times 2$ with W-S and P-NP as betweensubjects and $\mathrm{C}-\mathrm{R}$ as within-subjects factors. Both the recording equipment and the experimenter (the first author) were visible to the subjects. Writing was recorded with a videocassette recorder and analyzed with a studio-quality variable speed system that allowed reliable measurement to $0.1 \mathrm{sec}$. Spoken stories were recorded with audiocassette equipment and analyzed with a Siemens Oscillomink L and F-J fundamental frequency meter (Type FFM 6502), also to a minimum pause duration of $0.1 \mathrm{sec}$.

The overall goal of the research was to obtain a baseline of normative data for writing and of comparative data for writing and speaking: words and syllables per unit of time, duration of ontime units (phrases) between pauses, duration of offtime units (pauses) between phrases, total temporal and production units used (words, syllables, ontime, offtime), percentage of offtime/total time, and finally articulation rate (syllables/sec of ontime) and production (writing or speech) rate (syllables/sec of to- tal time). Graphemes were not used as an analytic unit because they have no exact parallel in speech; for example, punctuation itself is graphemic.

Several inferential hypotheses were also made. Articulation and production rates were expected to be higher for speaking than for writing. Speakers were accordingly expected to produce longer stories while using the same amount of time as writers. Longer pauses were expected in writing than in speaking and a higher percentage of offtime/total time was expected in the recall condition as a result of the memory load. Because the $P$ and NP conditions differed only in the recall phase, with the absence of the picture making reformulation of the story more difficult, longer pauses and a greater percentage of offtime/total time in the NP recall condition should manifest themselves in P-NP $\times C-R$ interactions.

Some additional hypotheses were made regarding duration of pauses in various writing positions. It was hypothesized that both punctuation and line-return positions would account for longer pauses in writing than would between-word and within-word positions. In the case of punctuation, the rationale is that punctuation generally corresponds to syntactic breaks. In the case of line returns, the rationale involves the additional time required to start a new line. Punctuation and line-return pauses were also hypothesized to be longer than the longest positional pauses in speaking and to reflect a much larger standard deviation of pause duration in writing than in speaking. These pauses cannot be compared directly with pause positions in speech, because speech lacks punctuation and line returns.

\section{RESULTS}

Temporal measures for the spoken stories can best be evaluated by comparison with a large set of storytelling data (representing the temporal analyses of narratives available in the archival literature) in Kowal, Wiese, and O'Connell (1983). Overall means (with Kowal et al.'s data in parentheses) were: speech rate, 2.92 syllables/sec (3.43); articulation rate, 4.51 syllables/sec (5.17); pause duration, $0.97 \mathrm{sec}(0.94)$; phrase length, 4.9 syllables (9.0); and percentage of offtime/total time, 34.1 (33.3). With the exception of pause duration, in which the difference is quite small anyway, and articulation rate, all differences are in a direction expected from the use of a shorter cutoff point $(0.1 \mathrm{sec})$ for minimum pause duration in the present experiment than in the data provided by Kowal et al. (1983).

To return to the main comparisons of the experiment, response measures were subjected to a 2 (W-S) $\times$ $2(\mathrm{P}-\mathrm{NP}) \times 2(\mathrm{C}-\mathrm{R})$ analysis of variance (in all cases, $d f=1,36$ ). Pause duration was the only response measure to show no significant effects across conditions. Of particular interest is the similarity across writing (mean $=1.00 \mathrm{sec}, S D=0.35$ ) and speaking (mean $=0.97 \mathrm{sec}$, $S D=0.71)$. In the analyses of all other response measures, the mean factors of modality (W-S) and composition-recall (C-R) were both significant. Means, standard deviations, $F \mathrm{~s}$, and $p$ s are reported in Table 1 . Note that the results for number of phrases are equally valid for number of pauses, because the latter is a simple transformation $(-1)$ of the number of phrases (number of pauses $=$ number of phrases minus one). The main factor of P-NP was significant only for percentage of offtime/total time (for $\mathrm{P}$, mean $=41.8 \%, S D=12.8$; for NP, mean $=34.5 \%, S D=12.3 ; F=5.09, p<.05)$. The only significant interaction was W-S $\times$ C-R for number of 
Table 1

Means, Standard Deviations (SDs), Fs, and ps for Main Factors of Writing-Speaking and Composition-Recall From ANOVAs for Five Response Measures

\begin{tabular}{|c|c|c|c|c|c|c|c|c|c|c|}
\hline \multirow[b]{2}{*}{ Response measure } & \multicolumn{2}{|c|}{ Writing } & \multicolumn{2}{|c|}{ Speaking } & \multirow[b]{2}{*}{$F$} & \multicolumn{2}{|c|}{ Composition } & \multicolumn{2}{|c|}{ Recall } & \multirow[b]{2}{*}{$\boldsymbol{F}$} \\
\hline & Mean & $\overline{S D}$ & Mean & $\overline{S D}$ & & Mean & $\overline{S D}$ & Mean & $\overline{S D}$ & \\
\hline $\begin{array}{l}\text { Number of words } \\
\text { Number of phrases } \\
\text { Phrase duration }(\mathrm{sec})\end{array}$ & $\begin{array}{c}67.7 \\
84.0 \\
1.33\end{array}$ & $\begin{array}{c}20.5 \\
34.9 \\
0.21\end{array}$ & $\begin{array}{c}106.4 \\
21.1 \\
1.67\end{array}$ & $\begin{array}{c}80.4 \\
16.3 \\
0.53\end{array}$ & $\begin{array}{r}6.11^{*} \\
74.50 \ddagger \\
13.15 \ddagger\end{array}$ & $\begin{array}{c}98.5 \\
58.8 \\
1.40\end{array}$ & $\begin{array}{c}79.1 \\
44.6 \\
0.38\end{array}$ & $\begin{array}{c}75.6 \\
46.2 \\
1.60\end{array}$ & $\begin{array}{c}33.5 \\
37.9 \\
0.47\end{array}$ & $\begin{array}{l}6.22^{*} \\
7.46^{*} \\
7.88 \dagger\end{array}$ \\
\hline $\begin{array}{l}\text { Offtime (sec) } \\
\text { Percentage of offtime/ } \\
\text { total time }\end{array}$ & $\begin{array}{l}82.3 \\
42.2\end{array}$ & $\begin{array}{r}35.5 \\
8.5\end{array}$ & $\begin{array}{l}20.1 \\
34.1\end{array}$ & $\begin{array}{l}20.1 \\
15.4\end{array}$ & $\begin{array}{r}65.56 \ddagger \\
6.28 *\end{array}$ & $\begin{array}{l}59.2 \\
40.8\end{array}$ & $\begin{array}{l}46.0 \\
11.9\end{array}$ & $\begin{array}{l}43.2 \\
35.5\end{array}$ & $\begin{array}{l}37.4 \\
13.6\end{array}$ & $\begin{array}{r}12.98 \ddagger \\
7.80 \dagger\end{array}$ \\
\hline
\end{tabular}

Note-All $d f \mathrm{~s}=1.36 . \quad{ }^{*} p<.025 . \quad \dagger p<.01 . \quad \ddagger p<.005$.

words; in writing, there was no notable decrease in words from $\mathrm{C}(68.5, S D=20.8)$ to $\mathrm{R}(66.9, S D=20.6)$, but a considerable decrease occurred in speaking (for $\mathrm{C}$, $128.4, S D=102.6$; for $\mathrm{R}, 84.4, S D=41.4 ; F=5.38$, $p<.05)$.

Mean duration, standard deviation, number, and percentage of total offtime in writing are presented in Table 2 . Because paragraphs were used by only a few subjects, paragraph data were not analyzed separately, but were combined with line returns. From Table 2 it is clear that although the within-word pauses were long (but not significantly so), they were infrequent and apparently reflected troubleshooting during composition. Text unitization or segmentation occurred at pauses between words. These were short and accounted for $64 \%$ of all pauses. They were the basic unitization element in this sample. This was clearly not the case for the spoken sample. Pauses at the word level, both within and between words, accounted for $73.1 \%$ of all pauses. Only $15.8 \%$ of pauses occurred before or after punctuation, providing a nice contrast to data from previous oral research. O'Connell and Kowal (1986) found that $91 \%$ of pause time was accounted for by punctuation in German homilies read aloud by the authors. This compares favorably with the $92 \%$ found by Van De Water and O'Connell (1985) in a corpus of poetry read aloud by the author. It should be noted that we cannot make a direct comparison between our writing and speaking samples because there are no written texts available for the latter group (i.e., we were dealing with spontaneous speech, not reading performance).

To return to Table 2 , then, the line return represents a combination of two things, margin and paper width $(21.5 \mathrm{~cm})$ and paragraph divisions. As stated earlier, the number of paragraph returns was so small that they did not significantly influence the mean duration; it is the line returns themselves that were long. Apparently, writers

Table 2

Mean Duration (in Seconds), Standard Deviation (SD), Number $(N)$, and Percentage of Total Offtime of Pauses in Writing

\begin{tabular}{lrrrr}
\hline \multicolumn{1}{c}{ Position } & Mean & $S D$ & \multicolumn{1}{c}{$N$} & $\begin{array}{r}\text { Percentage } \\
\text { of Offtime }\end{array}$ \\
\hline Within Words & 1.02 & 1.47 & 301 & 9.3 \\
Between Words & .80 & 1.13 & 2171 & 52.6 \\
Before Punctuation & 1.05 & 1.46 & 310 & 9.9 \\
After Punctuation & 1.83 & 2.45 & 223 & 12.4 \\
Line Returns & 1.37 & 1.49 & 379 & 15.8 \\
\hline
\end{tabular}

use line returns for more than simply moving down the page. They reflect variable line length despite constant paper width, variation in word length, and adjustment of punctuation priorities at line ends. Further empirical study on these variables is needed to clarify this issue. The high mean and standard deviation for pauses after punctuation seem to reflect primarily syntactic unitization. Writing pauses at the various types of punctuation appear to vary in duration quite widely and systematically, much as they do in oral reading (O'Connell and Kowal, 1986). The fairly high standard deviation of within-word (relative to between-word) pauses is probably due to a variety of search problems (what we have referred to as troubleshooting during composition).

The three shortest mean durations for pauses (within words, between words, and before punctuation) do not statistically differ from one another. However, the ANOVA for all five positions yielded $F(4,3379)=39.53$, $p<.001$. The line-return and after-punctuation pauses both reflect longer, major text segmentation due to syntax and the mechanics of the line. In addition, they are significantly different from all the others, as well as from each other $(p s<.05)$ by Scheffé tests. Their role in text segmentation should be studied further.

\section{DISCUSSION}

Correspondence of the spoken data obtained in the present experiment with that reviewed by Kowal et al. (1983) is quite close, despite the latter's heterogeneous data base. In general, the speech and articulation rates found in the present study were slow; in some cases, this fact will dictate conservative comparison with our writing data.

In general, speakers took only a fourth of the time taken by writers, but said more than half again as much as writers wrote. Although they produced fewer words, writers used four times as many phrases (and therefore four times as many pauses), and phrases of shorter duration (1.33 vs. $1.67 \mathrm{sec})$, although pauses were of comparable duration ( 1.00 vs. $0.97 \mathrm{sec}$ ). The percentage of offtime/total time was also lower for speaking than for writing, in keeping with Blass and Siegman's (1975) original hypothesis. With the exceptions of pause duration and words produced, these findings were all as we had hypothesized.

The expectation of longer mean pause duration was dictated by our knowledge that an appreciable number of long pauses occur in writing, pauses that do not characterize speaking at all (Kowal \& O'Connell, 1986; Matsuhashi \& Cooper, 1978). What we did not know in advance was that these longer pauses would be offset by far more short pauses, not characteristic of speaking, to yield pauses of equivalent mean duration for speaking and writing.

The mean pause duration of about $1 \mathrm{sec}$ in writing is far less than the mean durations discussed in our introduction. In fact, the only similar 
figure was obtained by Matsuhashi and Cooper (1978) in a control condition of rote copying. It is our conviction that previous instrumentation was not adequate to identify the many writing pauses that occur near the $0.1-\mathrm{sec}$ cutoff point. The result has been mean durations that were artifactually inflated.

The recall condition also yielded consistent significance. The hypothesized longer pauses, however, did not occur in recall. A smaller percentage of offtime/total time was used in recall than in composition. This response measure also yielded the only significant difference due to the P-NP variation. The presence of the picture yielded a higher percentage of offtime, which, it seems reasonable to assume, was used as viewing time; it was the P-NP factor that was significant, not the predicted interaction (P-NP $\times$ C-R). Number of words and phrases (and therefore pauses), as well as amount and percentage of offtime, decreased in recall. All but the last reflect, to some extent, forgetting; the decrease in percentage of offtime/total time reflects the absence of a picture to be viewed (for the NP subjects) as well as the inefficiency of the picture in eliciting further recall (for the P subjects). We found an increase in phrase duration in recall (1.60 sec, vs. $1.40 \mathrm{sec}$ for composition) that we had not hypothesized, and we can find no specific reason for it.

The WS-CR interaction for number of words indicates that more was forgotten by speakers than by writers (whose decrement of words was negligible). Nonetheless, speakers recalled more than the writers recalled or composed. Whether these differences reflect substantive differences in amount of propositional content or are due to stylistic elements (e.g., density of propositional content per word) cannot be assessed from these data.

None of our data on offtime confirm Gould's (1980) claim of " a constant proportion of total composition time" (p. 112) for planning. It is certainly reasonable to assume that planning goes on even during articulation (not only in offtime), but we have no valid formula that would yield a proportion of two thirds of composition time for planning.

The analysis of writing pauses is dependent on the density of punctuation, an index that is quite variable from subject to subject (see O'Connell \& Kowal, 1986; Van De Water \& O'Connell, 1986). Between-word pauses exhibit the most consistency of all writing pauses, because of the mechanics of writing. They exhibit the shortest mean duration and the smallest standard deviation, and account for the majority of both number of pauses $(64.2 \%)$ and amount of offtime $(52.6 \%)$. All of these elements must be taken into account if one is to characterize the time course of writing accurately.

A number of descriptive statistics require no further inferential logic. Number of syllables covaries with number of words. Of interest is the consistency of syllables per word across speaking and writing (1.35 vs. 1.39). The overall mean (1.37) is exactly the same as in the Gettysburg Address (van Bruggen, 1946) and The Lord's Prayer. A warning should be added, however: the syllables-per-word index does vary notably due to differences in group, genre, or language. Van Bruggen's findings, for example, have been criticized because of a considerable disparity in this index that went unnoticed (Kowal \& O'Connell, 1986). In the present study, both articulation and production rates differed by modality, but remained stable within modality across other conditions. There is no need for inferential statistics because there is no overlap whatsoever in the distributions. Articulation rates for speaking and writing were 4.51 and 0.89 syllables/sec, respectively; the corresponding production rates were 2.92 and 0.51 syllables/sec. In other words, speakers articulated five times as fast as writers and produced six times as fast (in view of the additional time spent by writers in pausing). This last difference is of considerable magnitude, and, in view of the fact that articulation rate was not analyzed separately for writing in the studies reviewed by Kowal and O'Connell (1986), it is also of considerable importance. For purposes of comparison, were we to use the articulation and speech rates (5.17 and 3.43 syllables/sec, respectively) from the archival data for storytelling (Kowal et al., 1983), speakers would be found to articulate six times as fast as writers and to produce almost seven times as fast. This factor of seven corresponds closely to that of both Blass and Siegman (1975) and Horowitz and Berkowitz (1964).

The writing rates obtained by Matsuhashi (1981) were extraordinarily slow, perhaps because subjects of high-school age were used. To compare Matsuhashi's writing rates with speech rates, we must make the assumption that Matsuhashi's data are characterized by 1.37 syllables per word, and we must convert mean writing rates of 0.22 (across the three experimental conditions) and 0.37 words/sec (in the control copying condition) into 0.30 and 0.51 syllables/sec, respectively. Speaking, then, is 9.7 (our data) or 11.4 (data of Kowal et al., 1983) times as fast as the experimental writing rate, or 5.7 (our data) or 6.7 (Kowal et al.'s data) times as fast as Matsuhashi's (1981) control writing rate. In other words, Matsuhashi's control data are much closer to our findings and to Kowal et al.'s (1983) data than to her own (1981) experimental data.

There is no easy way to study the time course of writing. One might hope that, even if the psycholinguists prefer to treat the sibling with neglect, we might be pressured by such fads as writing across the curriculum (e.g., Fulwiler, 1984) and other educational programs to allow the poor child back into the house.

\section{REFERENCES}

Blass, T., \& Siegman, A. W. (1975). A psycholinguistic comparison of speech, dictation and writing. Language \& Speech, 18, 20-34.

CHAFE, W. (1985). Linguistic differences produced by differences between speaking and writing. In D. R. Olson, N. Torrence, \& A. Hildyard (Eds.), Literacy, language, and learning (pp. 105-123). New York: Cambridge University Press.

ClaRK, H. H., \& Clark, E. V. (1977). Psychology and language. New York: Harcourt Brace Jovanovich.

DELL, G. S. (1986). A spreading activation theory of retrieval in sentence production. Psychological Review, 93, 283-321.

FULWILER, T. (1984). How well does writing across the curriculum work? College English, 46, 113-125.

GouLD, J. D. (1978). An experimental study of writing, dictating, and speaking. In J. Requin (Ed.), Attention and performance (Vol. 7). Hillsdale, NJ: Erlbaum.

GouLD, J. D. (1980). Experiments on composing letters: Some facts, some myths, and some observations. In L. W. Gregg \& E. R. Steinberg (Eds.), Cognitive processes in writing. Hillsdale, NJ: Erlbaum. GoulD, J. D., \& BoIEs, S. J. (1978). Writing, dictating, and speaking letters. Science, 201, 1145-1147.

Gould J. D., \& QUINONES, A. (1978). Handwriting and speech signal analyzer (IBM Technical Disclosure Bulletin, Disclosure No. Y08783045). Yorktown Heights, NY: Thomas J. Watson Research Center. Horowitz, M. W., \& BERKowITZ, A. (1964). Structural advantage of the mechanism of spoken expression as a factor in differences in spoken and written expression. Perceptual \& Motor Skills, 19, 619-625.

KoWAL, S., \& O'ConNELl, D. C. (1986). Writing as language behavior: Myths, models, methods. In A. Matsuhashi (Ed.), Writing in real time: Modelling production processes (pp. 108-132). New York: Ablex.

Kowal, S., Wiese, R., \& O'ConNell, D. C. (1983). The trouble with 'articulatory' pauses. Language \& Speech, 26, 203-214.

Matsuhashi, A. (1981). Explorations in the real-time production of written discourse. In M. Nystrand (Ed.), What writers know: The language, process, and structure of written discourse. New York: Academic Press.

Matsuhashi, A., \& CoOPER, C. (1978, March). A video time-monitored observational study: The transcribing behavior and composing processes of a competent high school writer. Paper presented at the meeting of the American Educational Research Association, Toronto, Ontario.

O’ConNell, D. C., \& Kowal, S. (1986). Use of punctuation for pausing: Oral readings by German radio homilists. Psychological Research, 48, 93-98.

Spittle, K. B., \& Matsuhashi, A. (1981). Semantic aspects of real time written discourse production. In M. Hairston \& C. Selfe (Eds.), Selected papers from the 1982 Texas Writing and Research Conference. University of Texas at Austin, Department of English.

Tannenbaum, P. H., Williams, F., \& Wood, B. S. (1967). Hesitation phenomena and related encoding characteristics in speech and typewriting. Language \& Speech, 10, 203-215.

vAN BRUGGEN, J. A. (1946). Factors affecting regularity of the flow of words during written composition. Journal of Experimental Education, 15, 133-155.

VAN De Water, D. A., \& O'Connell, D. C. (1985). In and about the poetic line. Bulletin of the Psychonomic Society, 23, 397-400.

(Manuscript received for publication October 16, 1986.) 